\title{
Effects of effective acute anti-hypertensive therapy on ischemic stroke prognosis: a meta-analysis of randomized controlled trials
}

\author{
Zhaokai Li \\ Xiangya Hospital Central South University \\ Yingxu Ma \\ The Second Xiangya Hospital, Central South Univeristy \\ Gan Huang \\ The Second Xiangya Hospital, Central South University \\ Guogang Zhang ( $\square$ zhangguogang@csu.edu.cn ) \\ Xiangya Hospital Central South University https://orcid.org/0000-0002-8678-2167
}

\section{Research article}

Keywords: Blood pressure, Anti-hypertensive therapy, Ischemic stroke, Acute phase, Meta-analysis

Posted Date: June 17th, 2020

DOI: https://doi.org/10.21203/rs.3.rs-35888/v1

License: (c) (i) This work is licensed under a Creative Commons Attribution 4.0 International License. Read Full License 


\section{Abstract}

Background: Although multiple randomized controlled trials (RCTs) and meta-analyses have been conducted on the issue of acute phase anti-hypertensive therapies for ischemic stroke (IS) patients, many studies have failed to enhance blood pressure (BP) decrease after these treatments. The effects of effective acute anti-hypertensive therapies on IS prognosis are still unclear.

Methods: Published literature was systematically searched in PubMed, Embase and Cochrane Library. Multiple RCTs that included IS patients, in which there was a significant BP decrease in the anti-hypertensive intervention group compared with the control group within $72 \mathrm{~h}$ after the onset of stroke, were identified. A meta-analysis was conducted to assess the effects of such therapy on the functional outcome, mortality, and multiple severe adverse events (SAEs) of IS patients.

Results: Eight RCTs were included in this study, with a total of 9427 IS patients. According to this meta-analysis, with significant BP differences between the treatment and control groups within $72 \mathrm{~h}$ from stroke onset, effective acute anti-hypertensive therapy has a neutral effect on multiple IS prognostic factors, including functional outcome (RR $1.03,95 \% \mathrm{Cl} 0.93-1.13)$, mortality ( $\mathrm{RR} 1.10,95 \% \mathrm{Cl} 0.89$ 1.35), and multiple SAEs.

Conclusions: Based on current studies, effective acute anti-hypertensive therapy did not improve the prognosis of IS patients, including functional outcome, mortality, and SAEs. There is no evidence that such therapy is beneficial in clinical practice.

\section{Introduction}

Stroke is one of the leading causes of death and severe disability. In 2013, it accounted for $11.8 \%$ of all deaths worldwide [1]. In the United States, more than 795,000 people suffer from stroke every year [2], with ischemic stroke (IS) accounting for most stroke cases [1, 2]. Although stroke can occur at any age, it has a higher prevalence and mortality in seniors [2]. With a globally aging population, the efficient management of this severe disease is increasingly becoming more important, and its prevention and treatments will provide benefits for the whole society.

In the management of IS patients, therapy in the acute phase is important to improve prognosis. Although the definition of the acute phase of IS varies due to different purposes and interventions [3, 4], it is widely accepted that during the first few days, when cerebral blood flow (CBF) is reduced due to ischemia, the pathophysiology in the infarcted brain changes rapidly and undergoes complex subcellular processes $[3,5,6]$. In the meantime, the blood pressure (BP) of patients significantly increases after the onset of IS [7]. This is the consequence of multiple factors, including pre-existing hypertension, mental stress, centrally mediated mechanisms, and neuroendocrine factors [8], and it is believed to be a kind of self-defending process of the human body. In most patients, the raised BP decreases dramatically in the first few days after the onset of stroke [9-11]. BP is related to cerebral collateral circulation and CBF [12]. While CBF is closely related to IS prognosis, the BP level after the onset of stroke is a strong factor in evaluating the prognosis of these patients. A Ushaped relationship between the initial BP after stroke onset and IS prognosis has been revealed $[8,10,13]$. In recent years, recombinant tissue plasminogen activator (rt-PA) therapy in the acute phase has significantly decreased the mortality of IS patients, and for patients who will be treated or have been recently treated with rt-PA therapy, it is recommended to slowly lower the systolic blood pressure (SBP) and diastolic blood pressure (DBP) to less than $185 \mathrm{mmHg}$ and $110 \mathrm{mmHg}$, respectively, which means that in such a situation, antihypertensive therapy is necessary [14]. However, for other IS patients whose BP is still higher than normal, the opinion on acute antihypertensive treatments remains controversial $[14,15]$.

Several large-scale randomized controlled trials (RCTs) regarding this topic have been conducted. Most of these studies used specific single drug or drugs combination as anti-hypertensive interventions, including angiotensin-converting enzyme inhibitors (ACEls) [16, 17], angiotensin II receptor blockers (ARBs) [18-20], beta blockers (BBs) [16], calcium-channel blockers (CCBs) [17, 21-25], diuretics [17], etc. Other studies reintroduced previous anti-hypertensive treatments to their treatment group but no anti-hypertensive treatments for their control group [26] or used intensive BP-lowering therapy as an intervention and guideline-recommended therapy as a control [27]. Neutral or near-neutral results have been observed in most of these studies. Nevertheless, as BP drops spontaneously and rapidly during the first few days for these patients, many RCTs in this field, such as Very Early Nimodipine Use in Stroke (VENUS) [24], failed to show a significant BP difference between the intervention and control groups after treatment. In some RCTs, such as the Continue Or Stop post-Stroke Antihypertensives Collaborative Study (COSSACS) [26], a significant difference in BP was found at 2 weeks after onset, which is too late to be considered in the acute phase. Thus, the efficiency of these studies in solving the issue of enhanced BP-lowering therapy on the prognosis of acute ischemic stroke (AIS) is limited. While these anti-hypertensive interventions can protect the central nervous system by decreasing BP, direct neuroprotective effects, which are irrelevant to their BP-lowering pharmacologic effects, have been reported for multiple therapies, including CCBs [28-30] and ARBs [31]. Other effects of these drugs have also been observed, including antiplatelet and 
anti-white cell effects [32]. These effects, which are seldomly related to the direct BP-lowering effect, should be minimized if BP management is the focus of studies in this field. Thus, to evaluate the effects of effective acute anti-hypertensive therapy on the prognosis of IS patients, a meta-analysis was conducted, in which only RCTs that reported a significant difference in BP between groups within $72 \mathrm{~h}$ were included.

\section{Methods}

This meta-analysis was conducted in accordance with the recommendations of the Preferred Reporting Items for Systematic reviews and Meta-Analyses (PRISMA) statement [33] and the Cochrane Handbook for Systematic Reviews of Interventions (version 6.0).

\section{Data sources and search strategy}

To screen for eligible RCTs, PubMed, Embase, and Cochrane Library were thoroughly searched, and the reference lists of published systematic reviews and meta-analyses were reviewed. The Cochrane Highly Sensitive Search Strategy [34] was used in the search process. In brief, the literature search was based on the following keywords: acute, ischemic stroke, blood pressure lowering or anti-hypertensive therapy, or the names of specific anti-hypertensive drugs. The acute phase cutoff threshold used in the current study was $72 \mathrm{~h}$, which was based on a previous meta-analysis [35] in this field. The anti-hypertensive drugs were in accordance with the most recent ACC/AHA and ESC/ESH hypertension guidelines $[14,36]$. The full search methods of these databases are available in additional file 1 . The last search was conducted on November 15, 2019. For each of the databases listed above, the reference lists from the earliest publication date available (i.e., 1970 for PubMed, 1956 for Embase, and 1984 for Cochrane Library) to the search date were screened for further selection.

\section{Selection criteria and quality assessment}

Studies fulfilling the following criteria were included for further assessment. (1) Large-scale RCTs: the study was an original RCT with more than 100 participants. (2) IS patients: the study population was IS patients, or it included an IS subgroup in acute stroke studies when the data of this subgroup were available. (3) Anti-hypertensive therapy: the additional treatment in the intervention group compared with the control group was one of the following: i. a specific anti-hypertensive drug or a combination of these drugs; ii. reintroduction of previous anti-hypertensive drugs; or iii. intensive anti-hypertensive treatments. (4) Acute phase intervention: the anti-hypertensive treatment was started within $72 \mathrm{~h}$ of symptom onset.

Studies that met one or more of the following criteria were excluded: (1) there was no difference in BP between groups after the antihypertensive treatment $(P>0.05)$ or BP decrease within $72 \mathrm{~h}$ of the onset was not mentioned; $(2)$ the data of the IS subgroup were not available in the original publication or subsequent related publications or could not be directly queried by the researchers.

Two reviewers ( $Z L$ and $Y M$ ), who were experts in medical evaluations and trained in the research methodology of the meta-analyses, independently screened the full titles and abstracts for relevance. Eligible studies with full text articles were identified independently by those two reviewers and were assessed based on the predetermined inclusion and exclusion criteria. Cohen's kappa was calculated to evaluate inter-rater agreement during the independent study selection [37]. The final list of included studies was decided on by discussion between the two reviewers, and if necessary, any remaining disagreements were resolved by a third reviewer (GZ).

The quality of the included RCTs was assessed with the Cochrane Collaboration's tool $[38,39]$ by the two investigators (ZL and YM) independently. Selection bias, performance bias, detection bias, attrition bias, reporting bias, and other bias were assessed. Discrepancies were resolved by discussion with a third investigator (GZ). The quality assessment was evaluated only for the measurement of potential bias and not for study exclusion.

\section{Data extraction and statistical analysis}

The data of IS patients within $72 \mathrm{~h}$ since onset were extracted by the two investigators independently using standard proforma. The name of the first author or the study and year of publication were used to uniquely identify each of the studies. In addition, the study design and characteristics, participant characteristics, and measurements of outcomes were extracted. If the study included stroke patients other than IS and the IS data were not available directly, the data of the IS subgroup were calculated from the data of all patients and subgroups of other kinds of stroke, which can be found in the original papers or related later-published subgroup studies. Alternatively, direct query by the researchers was performed for additional data if necessary. In studies with more than one intervention group, all intervention groups meeting the criteria for additional anti-hypertensive therapies were combined. Data were extracted into Review Manager software (version 5.3, offered by the Cochrane Collaboration), which was used to perform all downstream analyses. 
Outcomes were classified as functional outcome, mortality, and severe adverse events (SAEs) to comprehensively evaluate the prognosis of IS patients.

Functional outcome has been reported as the primary outcome in most studies in this field [16, 17, 20-22, 24, 25, 27]. In these studies, it often refers to death or dependency, which is defined as modified Rankin Scale (mRS) score $\geq 3$ or a relatively equivalent prognosis in other scales. Thus, we applied death or dependency as the primary outcome in this study. The period of reported outcomes varied from 7 days to 1 year for most studies in this field, so data in the short term (7-30 days) and long term (3 months or longer), along with their combination at the follow-up endpoint, were analyzed. The short-term and long-term definition here was modified from reported studies in this field [25, 35, 40-43]. For additional details on functional outcome, the distribution of mRS scores was assessed.

Mortality is also an important outcome to investigate. Mortality at the follow-up endpoint and short-term and long-term mortality were analyzed. For SAEs, to ensure representativeness and efficiency, only those SAEs for which data were available in at least 3 studies were analyzed in the current meta-analysis. The SAEs analyzed in this meta-analysis included the composite vascular endpoint (defined as the sum of vascular death, myocardial infarction or stroke events), hemorrhagic stroke events, ischemic stroke events, myocardial infarction events, and vascular death.

The risk ratio (RR) and $95 \%$ confidence intervals (Cls) of the intervention vs. control group were used to assess effects in this study since all included studies were RCTs, in which RR has been confirmed to be more suitable [44]. An effect with a $95 \% \mathrm{Cl}$ that does not contain 1 was considered significant; otherwise, it was considered nonsignificant and a neutral effect. Since the BP difference between groups after the intervention was the major cause of the effects by the original study design and the effects from enhanced BP lowering were hypothesized to be the same among studies, a fixed effects model was used as the default analysis model for all outcomes. $I^{2}$ tests were used to evaluate the clinical heterogeneity among the included studies, and an $1^{2} \geq 50 \%$ was considered to indicate significant heterogeneity. In the situation where statistical heterogeneity exists, the analysis model was changed to a random effects model. MantelHaenszel was used as the statistical method, and a funnel plot based on the primary outcome was used to evaluate possible publication bias. To further detect the robustness of the conclusion, sensitivity analysis was performed by changing the analysis model or excluding each of the studies to see whether a different conclusion for the $\mathrm{RR}$ and $95 \% \mathrm{Cl}$ is drawn.

\section{Results}

\section{Study selection}

After searching, a total of 5928 results were found from the 3 online databases. A total of 5141 articles remained after removing duplications, 17 of which were identified as qualified according to the inclusion criteria after manual screening. After reading the full-texts, 9 trials were excluded for the following reasons: (1) 8 trials [18, 23, 24, 26, 45-48] were excluded because no significant BP difference between groups within $72 \mathrm{~h}$ of onset occurred or BP decrease within $72 \mathrm{~h}$ of onset was not mentioned; and (2) 1 trial [49] was excluded because IS subgroup data were not available (Fig. 1). Cohen's kappa between the two reviewers (ZL and YM) during the independent study selection is 0.89 , which shows an almost perfect inter-rater agreement, while the discrepancies were solved later after discussion and involvement of the third reviewer (GZ). Finally, this meta-analysis included 8 RCTs [16, 17, 19-22, 25, 27], which comprised 9427 individuals with IS, with an equal assignment of the intervention group and the control group (4749 vs. $4678,50.4 \%$ vs. $49.6 \%$ ).

\section{Quality assessment and publication bias}

The 8 RCTs included 4 double-blind studies [16, 20-22] and 4 single-blind studies [17, 19, 25, 27]. According to the assessment with Cochrane Collaboration's tool, missing information was observed for the following: (1) allocation concealment [21, 22] and (2) selective reporting [25]. No evidence of other bias was shown in these 8 studies. Finally, all 8 studies were assessed to have good quality (Fig. 2). Publication bias was analyzed based on the effect of the primary outcome. The effect sizes of the included RCTs were distributed symmetrically (Fig. 3), which means no significant publication bias was observed in this study.

\section{Characteristics of the included studies and heterogeneity analysis}

The design and general characteristics of the eight RCTs $[16,17,19-22,25,27]$ included in this meta-analysis are summarized in Table 1. These studies were published between 1994 and 2019 and were conducted in 29 countries in total. Most patients were from Europe and Asia and have reduced the bias of race. Six studies $[17,19,21,22,25,27]$ included only IS patients, while the other two studies [16, 20] included patients with all types of stroke. The two relatively older studies $[21,22]$ did not set a specific inclusion SBP threshold, while the 
other studies had a lower threshold of SBP ranging from 140 to $160 \mathrm{mmHg}$. The total population in each study ranged from 172 (CHHIPS 2009 [16]) to 4071 (CATIS 2014 [17]). All participants were included within 2 days, as the designed inclusion time threshold for these studies ranged from 6 to $48 \mathrm{~h}$. The anti-hypertensive treatment in the enhanced BP intervention group was used for the first 3-21 days, which included ACEI, ARB, BB, CCB, and diuretics by using one or a combination of them. The follow-up period ranged from 3 months to 1 year for these studies, while the mean follow-up time of the patients who were included in the current meta-analysis was 4.07 months.

Table 1

Design and general characteristics of the included studies.

\begin{tabular}{|c|c|c|c|c|c|c|c|c|}
\hline Trial & Kaste 1994 & $\begin{array}{l}\text { INWEST } \\
2000\end{array}$ & $\begin{array}{l}\text { CHHIPS } \\
2009\end{array}$ & SCAST 2011 & CATIS 2014 & $\begin{array}{l}\text { VENTURE } \\
2015\end{array}$ & Li 2018 & $\begin{array}{l}\text { ENCHANTED } \\
2019\end{array}$ \\
\hline Country & Finland & $\begin{array}{l}11 \text { western } \\
\text { countries }\end{array}$ & $\begin{array}{l}\text { United } \\
\text { Kingdom }\end{array}$ & $\begin{array}{l}9 \text { north } \\
\text { European } \\
\text { countries }\end{array}$ & China & $\begin{array}{l}\text { South } \\
\text { Korea }\end{array}$ & China & 15 countries \\
\hline $\begin{array}{l}\text { Eligible BP } \\
\text { for } \\
\text { inclusion } \\
\text { (SBP, } \\
\text { mmHg) }\end{array}$ & $\mathrm{N} / \mathrm{A}$ & N/A & $>160$ & $>140$ & $140-220$ & $150-185$ & $160-220^{\#}$ & $>150$ \\
\hline $\begin{array}{l}\text { No. of total } \\
\text { patients } \\
\text { (IS\%) }\end{array}$ & 350 (100\%) & $\begin{array}{l}265^{*} \\
(100 \%)\end{array}$ & $\begin{array}{l}172 \\
(58 \%)\end{array}$ & 2029 (85\%) & 4071 (100\%) & $\begin{array}{l}393 \\
(100 \%)\end{array}$ & $\begin{array}{l}320 \\
(100 \%)\end{array}$ & 2196 (100\%) \\
\hline $\begin{array}{l}\text { Inclusion } \\
\text { from onset, } \\
\text { h }\end{array}$ & 48 & 24 & 36 & 30 & 48 & 24 & 48 & 6 \\
\hline $\begin{array}{l}\text { Intervention } \\
\text { period, } \\
\text { days }\end{array}$ & 21 & 21 & 14 & 7 & $\begin{array}{l}\text { During } \\
\text { hospitalization }\end{array}$ & 7 & $7^{+}$ & $3^{\$}$ \\
\hline $\begin{array}{l}\text { Agent, } \\
\text { intervention } \\
\text { vs. control }\end{array}$ & $\begin{array}{l}\text { Nimodipine } \\
\text { vs. Placebo }\end{array}$ & $\begin{array}{l}\text { Nimodipine } \\
\text { vs. Placebo }\end{array}$ & $\begin{array}{l}\text { Labetalol } \\
\text { or } \\
\text { Lisinopril } \\
\text { vs. } \\
\text { Placebo }\end{array}$ & $\begin{array}{l}\text { Candesartan } \\
\text { vs. Placebo }\end{array}$ & $\begin{array}{l}\text { ACEI, CCB, } \\
\text { diuretics vs. } \\
\text { None }\end{array}$ & $\begin{array}{l}\text { Valsartan } \\
\text { vs. None }\end{array}$ & $\begin{array}{l}\text { Amlodipine } \\
\text { or } \\
\text { Irbesartan } \\
\text { vs. None }\end{array}$ & $\begin{array}{l}\text { Intensive BP } \\
\text { lowering vs. } \\
\text { Guideline- } \\
\text { recommended } \\
\text { BP lowering }\end{array}$ \\
\hline $\begin{array}{l}\text { Follow-up } \\
\text { period, } \\
\text { months }\end{array}$ & 12 & 6 & 3 & 6 & 3 & 3 & 6 & 3 \\
\hline $\begin{array}{l}\text { \#Or with a DE } \\
\text { after onset, b } \\
\text { pressure; IS = }\end{array}$ & f $95-120$ & $\begin{array}{l}\mathrm{Hg} .{ }^{*} 295 \mathrm{pa} \\
\text { d conventic }\end{array}$ & $\begin{array}{l}\text { s were } 1 \\
\text { AT. }{ }^{\$} \mathrm{Ma}\end{array}$ & $\begin{array}{l}\text { ited, and } 265 \\
n \text { this BP lev }\end{array}$ & $\begin{array}{l}\text { tients were eli } \\
\text { or the next } 72\end{array}$ & $\begin{array}{l}\text { for eval } \\
\text { s. Abbre }\end{array}$ & $\begin{array}{l}\text { ion of the eff } \\
\text { ions: SBP = }\end{array}$ & $\begin{array}{l}\text { +One week } \\
\text { olic blood }\end{array}$ \\
\hline
\end{tabular}

The characteristics of the participants in these RCTs are shown in Table 2. The number of IS patients in the intervention group was comparable to that in the control group in six studies [17, 19-21, 25, 27], while in the other two studies [16, 22], it was about 2 times that of the control group because of the combination of two different doses. The age, sex, mean time to treatment since onset, baseline stroke severity, and baseline BP were comparable between groups in each study. The mean time since onset that participants received their first anti-hypertensive treatment was $13.1 \mathrm{~h}$. All studies showed a significant difference in BP between groups within $72 \mathrm{~h}$ since onset, while the decrease magnitude difference was for SBP in six studies [16, 17, 20, 22, 25, 27] and for DBP in seven studies [16, 17, 19-22, 25]. 
Table 2

Characteristics of the participants in the included studies.

\begin{tabular}{|c|c|c|c|c|c|c|c|c|}
\hline Trial & Kaste 1994 & $\begin{array}{l}\text { INWEST } \\
2000\end{array}$ & $\begin{array}{l}\text { CHHIPS } \\
2009\end{array}$ & $\begin{array}{l}\text { SCAST } \\
2011\end{array}$ & $\begin{array}{l}\text { CATIS } \\
2014\end{array}$ & $\begin{array}{l}\text { VENTURE } \\
2015\end{array}$ & Li 2018 & $\begin{array}{l}\text { ENCHANTED } \\
2019\end{array}$ \\
\hline $\begin{array}{l}\text { Number of IS patients, } \\
\text { Intervention vS. control, } \\
n\end{array}$ & 176 vs. 174 & $\begin{array}{l}173 \text { vs. } \\
92\end{array}$ & $\begin{array}{l}64 \text { vs. } \\
35\end{array}$ & $\begin{array}{l}862 \\
\text { VS. } \\
871\end{array}$ & $\begin{array}{l}2038 \\
\text { vs. } \\
2033\end{array}$ & $\begin{array}{l}195 \text { vs. } \\
198\end{array}$ & $\begin{array}{l}160 \mathrm{vs.} \\
160\end{array}$ & $\begin{array}{l}1081 \text { vs. } \\
1115\end{array}$ \\
\hline Age, y & 57 & 72 & 74 & 71 & 62 & 65 & 66 & 67 \\
\hline Male, \% & 67 & 46 & 56 & 58 & 64 & 59 & 66 & 62 \\
\hline $\begin{array}{l}\text { Mean time to treatment } \\
\text { from onset, } \mathrm{h}\end{array}$ & 20 & 11 & 19 & 18 & 15 & 12 & 21 & 3 \\
\hline Baseline stroke severity & $\begin{array}{l}32 \% \text { (percentage } \\
\text { of major stroke) } \#\end{array}$ & $\begin{array}{l}49 \\
\text { (Mathew } \\
\text { score) }\end{array}$ & $\begin{array}{l}9 \\
(\mathrm{NIHSS})\end{array}$ & $\begin{array}{l}41 \\
\text { (SSS) }\end{array}$ & $\begin{array}{l}4 \\
(\mathrm{NIHSS})\end{array}$ & $\begin{array}{l}3 \\
\text { (NIHSS) }\end{array}$ & $\begin{array}{l}8 \\
(\mathrm{NIHSS})\end{array}$ & 8 (NIHSS) \\
\hline Baseline SBP, mmHg & 156 & 160 & 182 & 171 & 166 & 163 & 183 & 165 \\
\hline Baseline DBP, mmHg & 92 & 89 & 95 & 90 & 97 & 91 & 104 & 91 \\
\hline $\begin{array}{l}\text { Time of significant BP } \\
\text { difference, } d\end{array}$ & $1 *$ & 2 & 1 & 2 & 1 & $3^{\$}$ & 3 & 1 \\
\hline SBP difference, $\mathrm{mmHg}$ & 1.9 & 10.2 & 10 & 3.3 & 8.2 & 2.1 & 5.78 & 5.5 \\
\hline DBP difference, mmHg & 4.9 & 9.1 & 3.4 & 1.3 & 3.7 & 2.9 & 2.74 & $\mathrm{~N} / \mathrm{A}$ \\
\hline
\end{tabular}

Heterogeneity analyses of each outcome were performed. The results showed no $\left(\mathrm{I}^{2}=0\right)$ or only little $\left(\mathrm{I}^{2}<50 \%\right)$ heterogeneity among the studies for most endpoints analyzed in this study, which was in line with our prediction. However, several other endpoints, including shortterm death or disability, $\mathrm{mRS}=0$, and composite vascular endpoint, showed considerable heterogeneity $\left(\mathrm{I}^{2} \geq 50 \%\right)$; thus, a random effects model was used for these endpoints.

\section{Functional outcome}

The primary outcome of this study was death or dependency at the study follow-up endpoint. This meta-analysis showed a neutral effect of anti-hypertensive therapy on death or dependency at the follow-up endpoint (RR 1.01, 95\% Cl 0.96-1.08, Fig. 4A). Similar results were also found for short-term (RR 1.06, 95\% Cl 0.93-1.22, Fig. 4B) and long-term (RR 1.00, 95\% Cl 0.93-1.06, Fig. 4C) death or dependency. Moreover, anti-hypertensive treatment showed no influence on the detailed functional outcome measured as mRS distribution (Table 3 ).

Table 3

Meta-analysis of the detailed functional outcome of mRS distribution at the study follow-up endpoint.

\begin{tabular}{|lll|}
\hline mRS & RR & $95 \% \mathrm{Cl}$ \\
\hline 0 & 1.04 & $0.88-1.22$ \\
\hline 1 & 0.95 & $0.89-1.02$ \\
\hline 2 & 1.02 & $0.93-1.11$ \\
\hline 3 & 0.97 & $0.87-1.08$ \\
\hline 4 & 0.95 & $0.85-1.07$ \\
\hline 5 & 1.12 & $0.92-1.37$ \\
\hline 6 & 1.13 & $0.97-1.32$ \\
\hline Abbreviations: $\mathrm{mRS}=$ modified Rankin Scale; $\mathrm{RR}=$ risk ratio; $\mathrm{Cl}=$ confidence interval. \\
\hline
\end{tabular}




\section{Mortality}

The mortality of these IS patients was also analyzed. Neutral effects were found for mortality at the follow-up endpoint (RR $1.13,95 \% \mathrm{Cl}$ 0.97-1.32, Fig. 5A), short-term mortality (RR 1.25, 95\% Cl 0.91-1.73, Fig. 5B) and long-term mortality (RR 1.11, 95\% Cl 0.94-1.31, Fig. 5C).

\section{SAES}

Furthermore, meta-analyses of several SAEs were conducted. Based on the included studies, a similar neutral influence was also found for these SAEs, including composite vascular endpoint (RR 0.89, 95\% Cl 0.72-1.10, Fig. 6A), hemorrhagic stroke events (RR $0.84,95 \% \mathrm{Cl}$ 0.49-1.45, Fig. 6B), ischemic stroke events ( $R R 1.38,95 \%$ Cl 0.96-1.98, Fig. 6C), myocardial infarction events (RR 1.06, 95\% Cl 0.58-1.93, Fig. 6D), and vascular death (RR 1.09, 95\% Cl 0.87-1.35, Fig. 6E).

\section{Sensitivity analysis}

Sensitivity analysis was performed for each outcome analyzed in this study. The conclusions for most outcomes did not change after the analysis model was changed or after excluding each included study (data not shown). Notably, a statistically significant increase in mortality was shown at the follow-up endpoint after CHHIPS 2009 [16] was excluded (RR 1.17, 95\% Cl 1.00-1.38).

\section{Discussion}

$\mathrm{BP}$ is one of the most important issues to be managed for IS patients in the acute phase, and whether an acute anti-hypertensive treatment aiming to reduce the elevated $\mathrm{BP}$ in such patients is beneficial has been a major question in the clinic. Controversial opinions and supportive evidence on both sides exist at the same time; thus, a systematic review of the available data was needed. In this study, with a systematic search for RCTs in IS patients, in which an enhanced BP decrease after the anti-hypertensive intervention within the acute phase was shown, a neutral (or near-harmful) effect of such therapy was found in the outcomes we analyzed. The results revealed that anti-hypertensive therapy has no evidence of providing a benefit to the prognosis of patients and could be an excessive medical treatment in clinical practice. In other words, unless otherwise indicated, anti-hypertensive treatment in the acute phase is not recommended for IS patients, in accordance with previous opinions in this field [36].

The neutral effect on functional outcome, i.e., death or dependency and mRS distribution, was also found in previous studies and metaanalyses [20,35, 41-43]. Death or disability after a stroke event has led to plenty of harm and placed burdens on stroke patients and their family members, and this was the most important prognosis [50]. For the medical team, functional outcome is one of the most important indexes to evaluate the prognosis of stroke patients. Thus, for the crucial clinical questions of functional outcome improvement, the content of a treatment and the timepoint to apply it for their patients is the most important consideration for physicians, and strong supportive evidence for these treatments is needed. Previous studies, including multiple meta-analyses [35, 41-43], tried to uncover the impact of anti-hypertensive therapies on functional outcome. All of these studies obtained neutral results, and they concluded that antihypertensive therapy has neither beneficial nor harmful effects on functional outcome and prognosis. This result has also been found in the current meta-analysis, which could be due to multiple reasons. From a pathophysiological view, the beneficial and harmful effects of BP-lowering therapy indeed exist simultaneously, which could neutralize each other and lead to unwanted functional outcomes and adverse event results. Of course, when more clinical trials related to this issue are available, preferably with a higher number of included patients and a longer follow-up period, it is possible that eventually a small but significant harmful effect can be found, but the current results indicate that such a therapy lacks evidence to be beneficial for IS patients.

Lowered BP by anti-hypertensive treatment for AIS patients revealed a slight but not significant harmful effect on mortality. BP was shown to be an important factor in the prognosis of ischemic stroke $[9,51,52]$. On the one hand, increased BP helps maintain cerebral perfusion via the direct induction of CBF and progressive vasoconstriction of arterioles [9]. On the other hand, less BP reduction is related to a higher perihematomal edema ratio and hematoma expansion [53], along with blood-brain barrier dysfunction [9]. The mortality results of this meta-analysis supported that these two opposite effects from BP reduction counteract each other in the rapidly changing pathophysiology during the acute phase when anti-hypertensive treatments were used. As the mortality for AIS patients showed a U-shaped curve in observational studies $[8,10,13]$, it is possible that these anti-hypertensive treatments have reduced BP to the "flat bottom" of the mortality curve, and neither beneficial nor unfavorable effects could be seen in the current study. Most previous studies showed a neutral effect on the mortality of these anti-hypertensive treatments, including most original RCTs $[17,20-22,25,27]$ and several systematic reviews [35, $42,43]$. The current meta-analysis excluded those studies that did not effectively decrease BP after anti-hypertensive treatment; thus, a lower variation and a higher absolute effect on mortality was achieved, but this effect was still not significant. However, with a 
nonsignificant result, a trend favoring the control group drew attention, especially in the sensitivity analysis, that a significant harmful effect of the lowered BP by anti-hypertensive therapy could be seen after CHHIPS 2009 [16] was excluded. Compared to the other studies, CHHIPS 2009 [16] had a relatively lower number of enrolled participants, higher average age of patients, and more severe baseline stroke severity (Table 2). Moreover, this study was premature because a significant beneficial effect was found from their anti-hypertensive treatment. Thus, the possibility of this study being biased cannot be excluded. Since the result shown here supported the harmfulness of effective anti-hypertensive treatment, it could at least partially reveal the possibility when more data are available in the future, and a stronger conclusion could be made. Careful consideration is needed when applying this result in clinical practice, but the potential harmful effect to increase mortality by such therapies needs to be taken into consideration. In addition, one previous meta-analysis [41] of both ischemic and hemorrhagic stroke patients showed that anti-hypertensive treatments increased short-term mortality, an effect that was not significant in the current study. In their study, a large portion of the effect was contributed by the BEST trial [49], which included both ischemic and hemorrhagic stroke patients who had mild symptoms on stroke onset compared with patients in other studies; thus, nonnegligible clinical heterogeneity existed between the BEST trial [49] and the studies enrolled in the current meta-analysis. The shortterm mortality in our study showed a trend preferring the control group, which is related but not fully equivalent to the result of this metaanalysis. In conclusion, a trend of harmful effects could be found in our study, which is worth taking into consideration, and a stronger and clearer conclusion in the future will need more large-scale RCTs that achieve significant BP differences between the intervention and control groups.

High BP is one of the most important and widely accepted risk factors for stroke events [2], and SBP level was shown to be related to recurrent stroke [54]. It is also reasonable that BP after IS onset, as one of the central cardiovascular indexes, has impacts on vascular events, including recurrent ischemic stroke and hemorrhagic stroke, and myocardial infarction events. In addition, disruption of the central nerve BP regulation reflex axis by the index stroke could lead to unfavorable influences, including these outcomes. However, in this study, the SAEs analyzed reflected neutral effects as well. One possible explanation could be that the available data were not enough to draw a clear conclusion, such as ischemic stroke events, for which only 3 RCTs were included, and for the relatively rare SAEs discussed here, including myocardial infarction events and hemorrhagic stroke events, only 41 and 51 events were reported in total, respectively. Small amounts of data from original studies were unable to reveal small effects, especially for those relatively rare events. Aside from our study, the previous meta-analyses also did not report positive results on these terms, which showed that these SAEs were of interest, but more data are needed. In the future, RCTs that report these SAEs are necessary for this field.

This study has several advantages. First, to our knowledge, this is the first meta-analysis that only included studies with a significant BP difference between groups; thus, the efficiency of the conclusions in this study was increased. Previous meta-analyses often mixed the results of all related RCTs together, which decreased the efficiency of revealing the real effect of enhanced BP decrease. On the one hand, the potential non-BP-lowering effects of these anti-hypertensive drugs could contribute to the prognosis of AlS patients. On the other hand, since the BP did not decrease significantly compared with that in the control group in these studies, its effect on prognosis could be buried by comparable amounts of effects other than BP lowering. In contrast, in the current meta-analysis, the studies that failed to see a significant difference in BP between treatment and control groups were excluded; thus, the influence of potential non-BP-lowering effects of these anti-hypertensive drugs was carefully decreased, and the effect of BP decrease was enlarged. Second, only the patients in the IS subgroup were included when the study population of the RCT was all stroke patients; thus, more detailed and precise results were made by this study. Hemorrhagic and ischemic stroke have different pathophysiological processes and different treatments in clinical practice, but many previous studies and meta-analyses did not differentiate between them, which led to a decreased power of their results. Finally, as the dynamic change in the brain infarcted area and hemodynamics within $72 \mathrm{~h}$ has a nonnegligible influence on prognosis and such an effect could change after the acute phase, the purification of effects from acute phase BP management also increased the significance of this study.

However, some limitations of this study still need to be mentioned. First, although heterogeneity analysis revealed that for most outcomes, the statistical heterogeneity was not considerable, and a random effects model was used for other outcomes, the clinical heterogeneity still calls for attention, since it can be potentially increased by multiple factors among different RCTs included in this study. The included RCTs have different interventions, including ACEls, ARBs, BBs, CCBs, diuretics, etc., which would increase the heterogeneity and potentially decrease the effectiveness because of the different pharmacological characteristics of these anti-hypertensive drugs. The patients included in this study had different initial severities of stroke. In addition, the extent of the significant BP difference and the timepoints it was observed among these studies were different. It is reasonable that a relationship exists between the extent of BP differences and outcomes, although such a relationship was hardly measured in our study because of the different baseline BPs among the included RCTs. In addition, if the BP has a larger effect in the superacute phase than later, or vice versa, which is possible, then a higher variability of the results would be observed. The factors mentioned above, including anti-hypertensive therapies, baseline stroke severity, and the extent and timepoint of significant BP difference, increased clinical heterogeneity and therefore decreased efficiency in searching for the

Page $8 / 17$ 
influence on the outcomes. Aside from that, except for the significantly increased mortality in the sensitivity analysis after excluding one study, we did not find any statistically significant effects from enhanced BP decrease. It is possible that such decreased BP is neither beneficial nor harmful for patients, but it is also possible that the number of included patients in currently available studies may not be enough to overcome the clinical heterogeneity among the RCTs and that the real effects were masked. In addition, the unavailability of specific individual data in the original RCTs included in the current meta-analysis limited further subgroup analyses and additional searches for the source of heterogeneity. Finally, although we tried to eliminate the effects of anti-hypertensive treatments used in RCTs other than BP lowering, these nonrelevant effects were minimized but not eliminated in the current study; thus, the results still need further discussion when applied in clinical practice.

\section{Conclusion}

This study concluded that in AIS patients, effective anti-hypertensive therapy within $72 \mathrm{~h}$ has a neutral effect on functional outcomes, mortality, and SAEs. In particular, a trend of a negative effect on mortality by these interventions was found, and new studies in this area are needed to clarify this issue. With more solid evidence, such therapies in the clinic are not recommended. This conclusion could help increase the beneficial outcomes of AIS patients and decrease their burden.

\section{List Of Abbreviations}

ACEl: Angiotensin-converting enzyme inhibitor; AIS: Acute ischemic stroke; ARB: Angiotensin II receptor blocker; BB: Beta blocker; BEST: The beta blocker stroke; BP: Blood pressure; CATIS: The China Antihypertensive Trial in Acute Ischemic Stroke; CBF: Cerebral blood flow; CCB: Calcium-channel blocker; CHHIPS: Controlling hypertension and hypotension immediately post-stroke; Cl: Confidence interval; COSSACS: The Continue Or Stop post-Stroke Antihypertensives Collaborative Study; DBP: Diastolic blood pressure; ENCHANTED: The Enhanced Control of Hypertension and Thrombolysis Stroke Study; INWEST: Intravenous Nimodipine West European Stroke Trial; IS: Ischemic stroke; mRS: modified Rankin Scale; NIHSS: National Institutes of Health Stroke Scale; PRISMA: Preferred Reporting Items for Systematic reviews and Meta-Analyses; PRoFESS: The Prevention Regimen for Effectively Avoiding Second Strokes; RCTs: Randomized controlled trials; RR: Risk ratio; rt-PA: recombinant tissue Plasminogen Activator; SAEs: Severe adverse events; SBP: Systolic blood pressure; SCAST: The Scandinavian Candesartan Acute Stroke Trial; SE: Standard error; SSS: Scandinavian Stroke Scale; VENTURE: The Valsartan Efficacy oN modesT blood pressUre REduction in acute ischemic stroke; VENUS: Very Early Nimodipine Use in Stroke.

\section{Declarations}

\section{Ethics approval and consent to participate}

Not applicable.

\section{Consent for publication}

The manuscript has been approved by all authors for publication.

\section{Availability of data and materials}

Because this is a meta-analysis, all data included in the current study could be found in the included references.

\section{Competing interests}

The authors declare that they have no competing interests.

\section{Funding}

None.

\section{Authors' contributions}

GZ and ZL conceived the idea and contributed to the study design. ZL and YM contributed to the literature search and data extraction. ZL and GH participated in the statistical analyses and prepared the figures. GZ supervised the study. ZL drafted the manuscript. All authors (ZL, YM, GH, and GZ) critically revised the manuscript and approved the final version for publication. 


\section{Acknowledgments}

We thank of American Journal Experts (AJE, www.aje.com), for editing the English text of this manuscript.

\section{References}

1. Feigin VL, Norrving B, Mensah GA. Global Burden of Stroke. Circ Res. 2017;120 3:439-48; doi: 10.1161/CIRCRESAHA.116.308413.

2. Benjamin EJ, Blaha MJ, Chiuve SE, Cushman M, Das SR, Deo R, et al. Heart Disease and Stroke Statistics-2017 Update: A Report From the American Heart Association. Circulation. 2017;135 10:e146-e603; doi: 10.1161/CIR.0000000000000485.

3. Catanese L, Tarsia J, Fisher M. Acute Ischemic Stroke Therapy Overview. Circ Res. 2017;120 3:541-58; doi: 10.1161/CIRCRESAHA.116.309278.

4. Leng X, Leung TW, Wong KSL. Antiplatelet therapy after stroke: should it differ in the acute and chronic phase after stroke. Curr Opin Neurol. 2018;31 1:14-22; doi: 10.1097/WC0.0000000000000509.

5. Puyal J, Ginet V, Clarke PG. Multiple interacting cell death mechanisms in the mediation of excitotoxicity and ischemic brain damage: a challenge for neuroprotection. Prog Neurobiol. 2013;105:24-48; doi: 10.1016/j.pneurobio.2013.03.002.

6. Descloux C, Ginet V, Clarke PG, Puyal J, Truttmann AC. Neuronal death after perinatal cerebral hypoxia-ischemia: Focus on autophagymediated cell death. Int J Dev Neurosci. 2015;45:75-85; doi: 10.1016/j.ijdevneu.2015.06.008.

7. Qureshi Al, Ezzeddine MA, Nasar A, Suri MF, Kirmani JF, Hussein HM, et al. Prevalence of elevated blood pressure in 563,704 adult patients with stroke presenting to the ED in the United States. Am J Emerg Med. 2007;25 1:32-8; doi: 10.1016/j.ajem.2006.07.008.

8. Bangalore S, Schwamm L, Smith EE, Hellkamp AS, Suter RE, Xian Y, et al. Blood pressure and in-hospital outcomes in patients presenting with ischaemic stroke. Eur Heart J. 2017;38 37:2827-35; doi: 10.1093/eurheartj/ehx330.

9. Qureshi Al. Acute hypertensive response in patients with stroke: pathophysiology and management. Circulation. 2008;118 2:176-87; doi: 10.1161/CIRCULATIONAHA.107.723874.

10. Tikhonoff V, Zhang HF, Richart T, Staessen JA. Blood pressure as a prognostic factor after acute stroke. Lancet Neurol. 2009;8 10:93848; doi: Doi 10.1016/S1474-4422(09)70184-X.

11. Tomii Y, Toyoda K, Suzuki R, Naganuma M, Fujinami J, Yokota C, et al. Effects of 24-hour blood pressure and heart rate recorded with ambulatory blood pressure monitoring on recovery from acute ischemic stroke. Stroke. 2011;42 12:3511-7; doi:

10.1161/STROKEAHA.111.628586.

12. Shuaib A, Butcher K, Mohammad AA, Saqqur M, Liebeskind DS. Collateral blood vessels in acute ischaemic stroke: a potential therapeutic target. Lancet Neurol. 2011;10 10:909-21; doi: 10.1016/S1474-4422(11)70195-8.

13. Castillo J, Leira R, Garcia MM, Serena J, Blanco M, Davalos A. Blood pressure decrease during the acute phase of ischemic stroke is associated with brain injury and poor stroke outcome. Stroke. 2004;35 2:520-6; doi: 10.1161/01.STR.0000109769.22917.B0.

14. Whelton PK, Carey RM, Aronow WS, Casey DE, Jr., Collins KJ, Dennison Himmelfarb C, et al. 2017 ACC/AHA/AAPA/ABC/ACPM/AGS/APhA/ASH/ASPC/NMA/PCNA Guideline for the Prevention, Detection, Evaluation, and Management of High Blood Pressure in Adults: A Report of the American College of Cardiology/American Heart Association Task Force on Clinical Practice Guidelines. J Am Coll Cardiol. 2018;71 19:e127-e248; doi: 10.1016/j.jacc.2017.11.006.

15. Powers WJ, Rabinstein AA, Ackerson T, Adeoye OM, Bambakidis NC, Becker K, et al. 2018 Guidelines for the Early Management of Patients With Acute Ischemic Stroke: A Guideline for Healthcare Professionals From the American Heart Association/American Stroke Association. Stroke. 2018;49 3:e46-e110; doi: 10.1161/STR.0000000000000158.

16. Potter JF, Robinson TG, Ford GA, Mistri A, James M, Chernova J, et al. Controlling hypertension and hypotension immediately poststroke (CHHIPS): a randomised, placebo-controlled, double-blind pilot trial. Lancet Neurol. 2009;8 1:48-56; doi: 10.1016/S14744422(08)70263-1.

17. He J, Zhang Y, Xu T, Zhao Q, Wang D, Chen CS, et al. Effects of immediate blood pressure reduction on death and major disability in patients with acute ischemic stroke: the CATIS randomized clinical trial. JAMA. 2014;311 5:479-89; doi: 10.1001/jama.2013.282543.

18. Schrader J, Luders S, Kulschewski A, Berger J, Zidek W, Treib J, et al. The ACCESS Study: evaluation of Acute Candesartan Cilexetil Therapy in Stroke Survivors. Stroke. 2003;34 7:1699-703; doi: 10.1161/01.STR.0000075777.18006.89.

19. Oh MS, Yu KH, Hong KS, Kang DW, Park JM, Bae HJ, et al. Modest blood pressure reduction with valsartan in acute ischemic stroke: a prospective, randomized, open-label, blinded-end-point trial. Int J Stroke. 2015;10 5:745-51; doi: 10.1111/ijs.12446.

20. Sandset EC, Bath PM, Boysen G, Jatuzis D, Korv J, Luders S, et al. The angiotensin-receptor blocker candesartan for treatment of acute stroke (SCAST): a randomised, placebo-controlled, double-blind trial. Lancet. 2011;377 9767:741-50; doi: 10.1016/S0140- 
6736(11)60104-9.

21. Kaste M, Fogelholm R, Erila T, Palomaki H, Murros K, Rissanen A, et al. A randomized, double-blind, placebo-controlled trial of nimodipine in acute ischemic hemispheric stroke. Stroke. 1994;25 7:1348-53; doi: 10.1161/01.str.25.7.1348.

22. Ahmed N, Nasman P, Wahlgren NG. Effect of intravenous nimodipine on blood pressure and outcome after acute stroke. Stroke. 2000;31 6:1250-5; doi: 10.1161/01.str.31.6.1250.

23. Gelmers HJ, Gorter K, de Weerdt CJ, Wiezer HJ. A controlled trial of nimodipine in acute ischemic stroke. N Engl J Med. 1988;318 4:203-7; doi: 10.1056/NEJM198801283180402.

24. Horn J, de Haan RJ, Vermeulen M, Limburg M. Very Early Nimodipine Use in Stroke (VENUS): a randomized, double-blind, placebocontrolled trial. Stroke. 2001;32 2:461-5; doi: 10.1161/01.str.32.2.461.

25. Li Y, Zhong Z, Luo S, Han X, Liang Y, Huang G, et al. Efficacy of Antihypertensive Therapy in the Acute Stage of Cerebral Infarction - A Prospective, Randomized Control Trial. Acta Cardiologica Sinica. 2018;34 6:502-10; doi: 10.6515/ACS.201811_34(6).20180622B.

26. Robinson TG, Potter JF, Ford GA, Bulpitt CJ, Chernova J, Jagger C, et al. Effects of antihypertensive treatment after acute stroke in the Continue or Stop Post-Stroke Antihypertensives Collaborative Study (COSSACS): a prospective, randomised, open, blinded-endpoint trial. Lancet Neurol. 2010;9 8:767-75; doi: 10.1016/S1474-4422(10)70163-0.

27. Anderson CS, Huang Y, Lindley RI, Chen X, Arima H, Chen G, et al. Intensive blood pressure reduction with intravenous thrombolysis therapy for acute ischaemic stroke (ENCHANTED): an international, randomised, open-label, blinded-endpoint, phase 3 trial. Lancet. 2019;393 10174:877-88; doi: 10.1016/S0140-6736(19)30038-8.

28. Wahlgren NG, Ahmed N. Neuroprotection in cerebral ischaemia: facts and fancies-the need for new approaches. Cerebrovasc Dis. 2004;17 Suppl 1:153-66; doi: 10.1159/000074808.

29. Sobrado M, Lopez MG, Carceller F, Garcia AG, Roda JM. Combined nimodipine and citicoline reduce infarct size, attenuate apoptosis and increase bcl-2 expression after focal cerebral ischemia. Neuroscience. 2003;118 1:107-13; doi: 10.1016/s0306-4522(02)00912-0.

30. Ginsberg MD. Neuroprotection for ischemic stroke: past, present and future. Neuropharmacology. 2008;55 3:363-89; doi: 10.1016/j.neuropharm.2007.12.007.

31. Villapol S, Saavedra JM. Neuroprotective effects of angiotensin receptor blockers. Am J Hypertens. 2015;28 3:289-99; doi: 10.1093/ajh/hpu197.

32. Bath PM, Appleton JP, Krishnan K, Sprigg N. Blood Pressure in Acute Stroke: To Treat or Not to Treat: That Is Still the Question. Stroke. 2018;49 7:1784-90; doi: 10.1161/STROKEAHA.118.021254.

33. Moher D, Liberati A, Tetzlaff J, Altman DG, Group P. Preferred reporting items for systematic reviews and meta-analyses: the PRISMA statement. BMJ. 2009;339:b2535; doi: 10.1136/bmj.b2535.

34. Ma Y, Bai F, Qin F, Li J, Liu N, Li D, et al. Beta-blockers for the primary prevention of anthracycline-induced cardiotoxicity: a metaanalysis of randomized controlled trials. BMC Pharmacol Toxicol. 2019;20 1:18; doi: 10.1186/s40360-019-0298-6.

35. Lee M, Ovbiagele B, Hong KS, Wu YL, Lee JE, Rao NM, et al. Effect of Blood Pressure Lowering in Early Ischemic Stroke: MetaAnalysis. Stroke. 2015;46 7:1883-9; doi: 10.1161/STROKEAHA.115.009552.

36. Williams B, Mancia G, Spiering W, Agabiti Rosei E, Azizi M, Burnier M, et al. 2018 ESC/ESH Guidelines for the management of arterial hypertension. Eur Heart J. 2018;39 33:3021-104; doi: 10.1093/eurheartj/ehy339.

37. Woolen SA, Shankar PR, Gagnier JJ, MacEachern MP, Singer L, Davenport MS. Risk of Nephrogenic Systemic Fibrosis in Patients With Stage 4 or 5 Chronic Kidney Disease Receiving a Group II Gadolinium-Based Contrast Agent: A Systematic Review and Meta-analysis. JAMA Intern Med. 2019; doi: 10.1001/jamainternmed.2019.5284.

38. Yin SH, Xu P, Wang B, Lu Y, Wu QY, Zhou ML, et al. Duration of dual antiplatelet therapy after percutaneous coronary intervention with drug-eluting stent: systematic review and network meta-analysis. BMJ. 2019;365:I2222; doi: 10.1136/bmj.I2222.

39. Ma Y, Bai F, Qin F, Li Y, Tu T, Sun C, et al. Catheter ablation for treatment of patients with atrial fibrillation and heart failure: a metaanalysis of randomized controlled trials. BMC Cardiovasc Disord. 2018;18 1:165; doi: 10.1186/s12872-018-0904-3.

40. Collins TC, Petersen NJ, Menke TJ, Souchek J, Foster W, Ashton CM. Short-term, intermediate-term, and long-term mortality in patients hospitalized for stroke. J Clin Epidemiol. 2003;56 1:81-7; doi: 10.1016/s0895-4356(02)00570-x.

41. Wang H, Tang Y, Rong X, Li H, Pan R, Wang Y, et al. Effects of early blood pressure lowering on early and long-term outcomes after acute stroke: an updated meta-analysis. PLoS One. 2014;9 5:e97917; doi: 10.1371/journal.pone.0097917.

42. Zhao R, Liu FD, Wang S, Peng JL, Tao XX, Zheng B, et al. Blood Pressure Reduction in the Acute Phase of an Ischemic Stroke Does Not Improve Short- or Long-Term Dependency or Mortality: A Meta-Analysis of Current Literature. Medicine (Baltimore). 2015;94 23:e896; doi: 10.1097/MD.0000000000000896. 
43. Liu S, Li C, Li T, Xiong J, Zhao X. Effects of Early Hypertension Control after Ischaemic Stroke on the Outcome: A Meta-Analysis. Cerebrovasc Dis. 2015;40 5-6:270-8; doi: 10.1159/000441097.

44. Deeks JJ. Issues in the selection of a summary statistic for meta-analysis of clinical trials with binary outcomes. Stat Med. 2002;21 11:1575-600; doi: 10.1002/sim.1188.

45. Trust Study G. Randomised, double-blind, placebo-controlled trial of nimodipine in acute stroke. The Lancet. 1990;336 8725:1205-9; doi: 10.1016/0140-6736(90)92829-7.

46. Martinez-Vila E, Guillen F, Villanueva JA, Matias-Guiu J, Bigorra J, Gil P, et al. Placebo-controlled trial of nimodipine in the treatment of acute ischemic cerebral infarction. Stroke. 1990;21 7:1023-8; doi: 10.1161/01.str.21.7.1023.

47. Group TANS. Clinical trial of nimodipine in acute ischemic stroke. The American Nimodipine Study Group. Stroke. 1992;23 1:3-8; doi: 10.1161/01.str.23.1.3.

48. Norris JW, LeBrun LH, Anderson BA. Intravenous Nimodipine in Acute Ischaemic Stroke. Cerebrovascular Diseases. 1994;4 3:194-6; doi: 10.1159/000108481.

49. Barer DH, Cruickshank JM, Ebrahim SB, Mitchell JR. Low dose beta blockade in acute stroke ("BEST" trial): an evaluation. Br Med J (Clin Res Ed). 1988;296 6624:737-41; doi: 10.1136/bmj.296.6624.737.

50. Kissela B, Lindsell CJ, Kleindorfer D, Alwell K, Moomaw CJ, Woo D, et al. Clinical prediction of functional outcome after ischemic stroke: the surprising importance of periventricular white matter disease and race. Stroke. 2009;40 2:530-6; doi: 10.1161/STROKEAHA.108.521906.

51. Willmot M, Leonardi-Bee J, Bath PM. High blood pressure in acute stroke and subsequent outcome: a systematic review. Hypertension. 2004;43 1:18-24; doi: 10.1161/01.HYP.0000105052.65787.35.

52. Yong M, Kaste M. Association of characteristics of blood pressure profiles and stroke outcomes in the ECASS-II trial. Stroke. 2008;39 2:366-72; doi: 10.1161/STROKEAHA.107.492330.

53. Qureshi Al, Palesch YY, Martin R, Novitzke J, Cruz-Flores S, Ehtisham A, et al. Effect of systolic blood pressure reduction on hematoma expansion, perihematomal edema, and 3-month outcome among patients with intracerebral hemorrhage: results from the antihypertensive treatment of acute cerebral hemorrhage study. Arch Neurol. 2010;67 5:570-6; doi: 10.1001/archneurol.2010.61.

54. Ovbiagele B, Diener HC, Yusuf S, Martin RH, Cotton D, Vinisko R, et al. Level of systolic blood pressure within the normal range and risk of recurrent stroke. JAMA. 2011;306 19:2137-44; doi: 10.1001/jama.2011.1650.

\section{Figures}




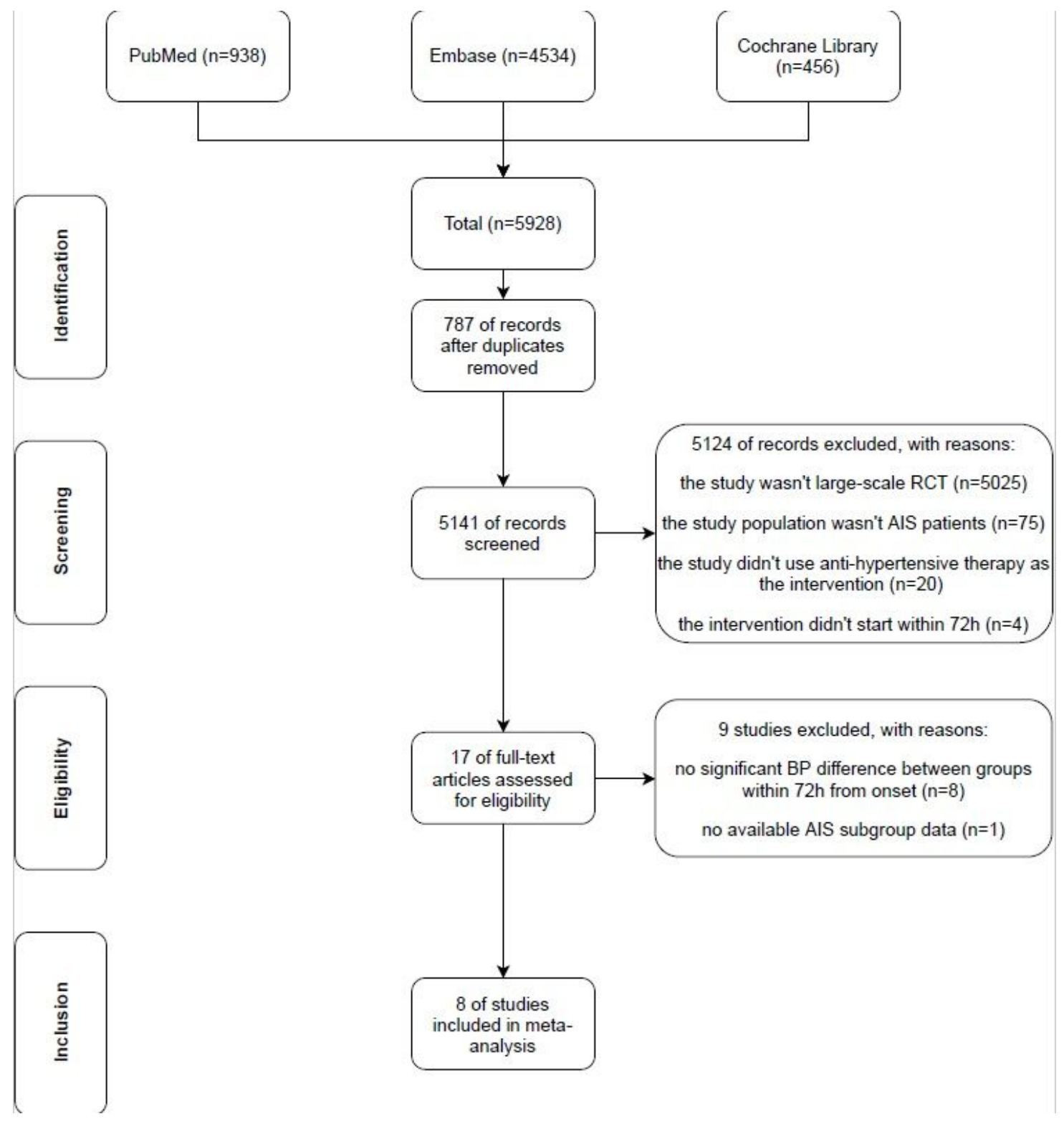

Figure 1

Flow chart of clinical trial selection. A total of 6696 records were originally found, and 7 studies were included in the final meta-analysis. 

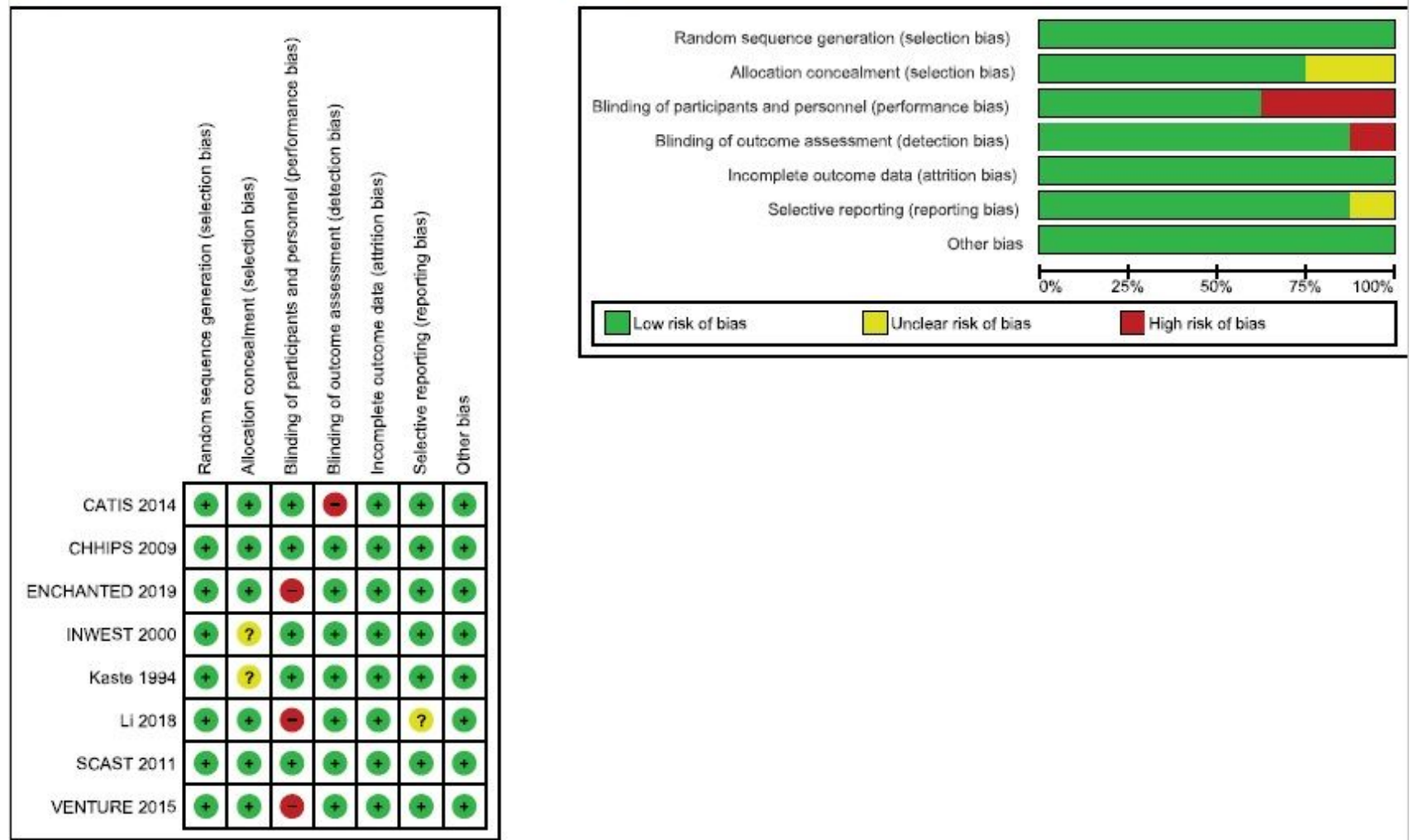

\section{Figure 2}

Quality assessment tables of the included RCTs. (A) Risk of bias summary. (B) Risk of bias graph.

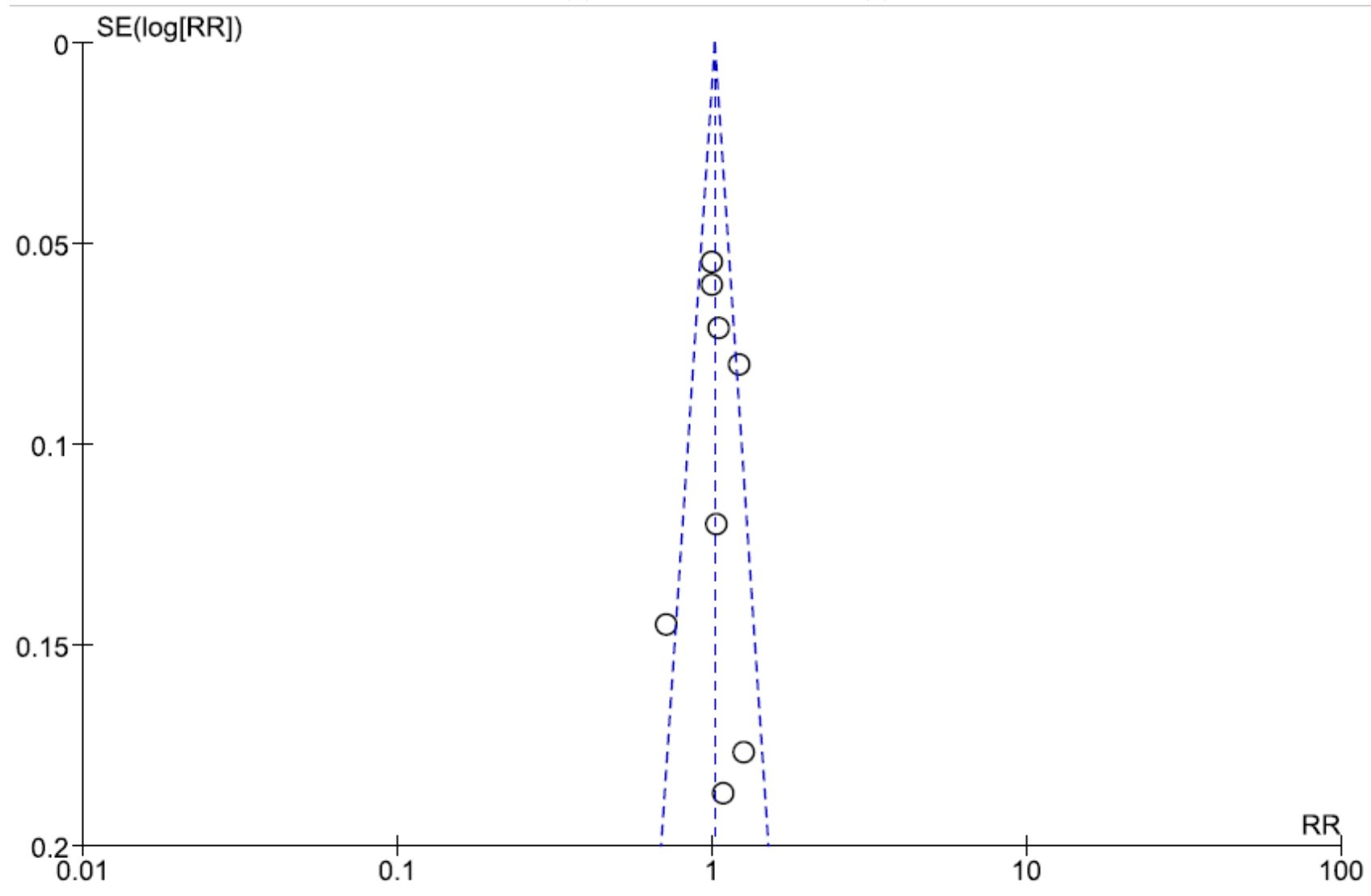

Figure 3 
Funnel plot for publication bias based on death or dependency at the follow-up endpoint. Abbreviations: SE=standard error; RR=risk ratio.

A

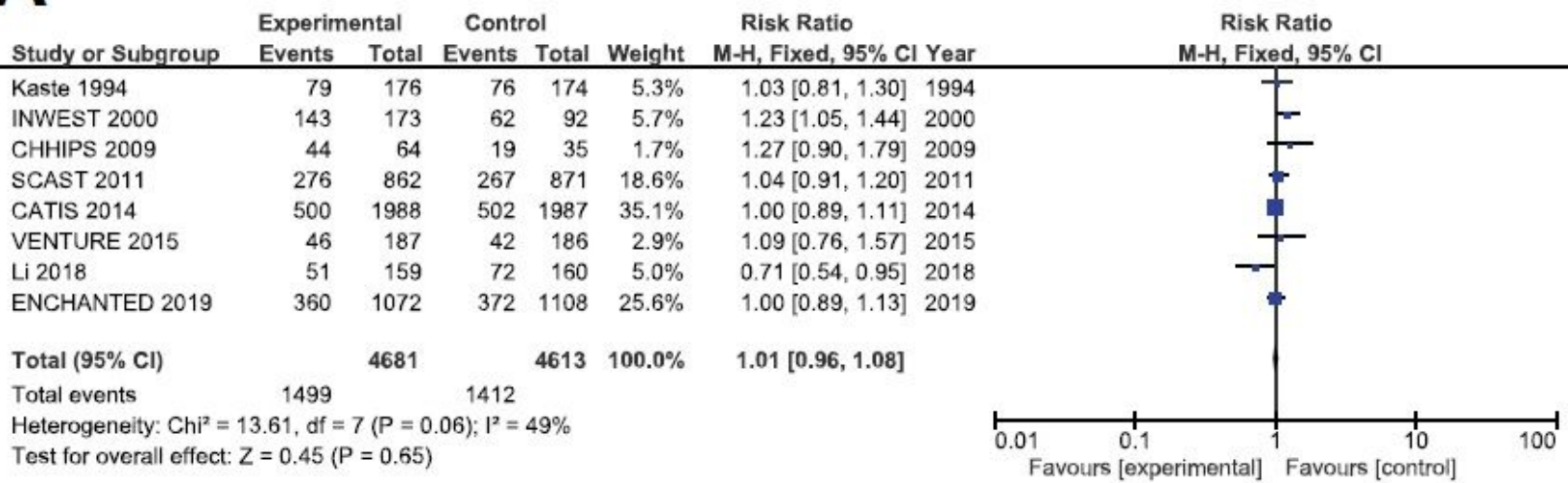

B

\begin{tabular}{lllll} 
& \multicolumn{2}{c}{ Experimental } & Control & Risk Ratio \\
Study or Subgroup & Events Total Events Total Weight & M-H, Randorn, $95 \% \mathrm{Cl}$ Year
\end{tabular}

$123[1.05,1.44] 2000$

$\begin{array}{llllll}\text { CHHIPS } 2009 & 44 & 64 & 19 & 35 & 11.2 \%\end{array}$

$\begin{array}{llllll}\text { CATIS } 2014 & 683 & 2038 & 681 & 2033 & 36.1 \%\end{array}$

Li $2018 \quad 98 \quad 160 \quad 106 \quad 160 \quad 25.9 \%$

$1.27[0.90,1.79] 2009$

$1.00[0.92,1.09] 2014$

$0.92[0.78,1.09] 2018$

Total $(95 \% \mathrm{CI})$

Total events

2435

Heterogeneity: Tau $^{2}=0.01 ; \mathrm{Chi}^{2}=8.32, \mathrm{df}=3(P=0.04) ; I^{2}=64 \%$

Test for overall effect: $Z=0.89(P=0.37)$

$1.06[0.93,1.22]$

C

Experimental Control

Risk Ratio

Risk Ratio

M-H, Random, $95 \%$ Cl

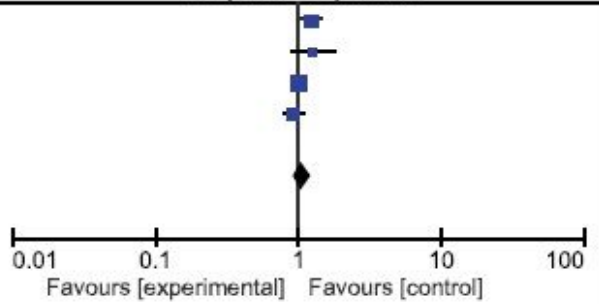

Study or Subgroup Events Total Events Total Weight M-H, Fixed, 95\% Cl Year

\begin{tabular}{|c|c|c|c|c|c|c|c|c|c|c|}
\hline & & & & & & 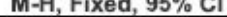 & & (1) & (1) & \\
\hline Kaste 1994 & 79 & 176 & 76 & 174 & $5.8 \%$ & $1.03[0.81,1.30]$ & 1994 & & $F$ & \\
\hline SCAST 2011 & 276 & 862 & 267 & 871 & $20.1 \%$ & $1.04[0.91,1.20]$ & 2011 & & & \\
\hline CATIS 2014 & 500 & 1988 & 502 & 1987 & $37.9 \%$ & $1.00[0.89,1.11]$ & 2014 & & & \\
\hline VENTURE 2015 & 46 & 187 & 42 & 186 & $3.2 \%$ & $1.09[0.76,1.57]$ & 2015 & & & \\
\hline Li 2018 & 51 & 159 & 72 & 160 & $5.4 \%$ & $0.71[0.54,0.95]$ & 2018 & & & \\
\hline ENCHANTED 2019 & 360 & 1072 & 372 & 1108 & $27.6 \%$ & $1.00[0.89,1.13]$ & 2019 & & & \\
\hline Total $(95 \% \mathrm{Cl})$ & & 4444 & & 4486 & $100.0 \%$ & $1.00[0.93,1.06]$ & & & & \\
\hline Total events & 1312 & & 1331 & & & & & & & \\
\hline \multicolumn{8}{|c|}{ Heterogeneity: $\mathrm{Chi}^{2}=6.09, \mathrm{df}=5(\mathrm{P}=0.30) ; \mathrm{I}^{2}=18 \%$} & $\lcm{\longmapsto} 0.01$ & 10 & $\overrightarrow{100}$ \\
\hline \multicolumn{11}{|c|}{ Test for overall effect: $Z=0.12(P=0.91) \quad$ Favours [experimental] Favours [control] } \\
\hline
\end{tabular}

Figure 4

Comparison of death or dependency between the intervention and control groups. A. Death or dependency at the study follow-up endpoint. B. Short-term death or dependency. C. Long-term death or dependency. Death or dependency is defined as mRS $>=3$ or relatively matched prognosis in other scales. Long-term treatment was defined as 3 months or longer. Short-term was defined as 7-30 days. Abbreviation: mRS=modified Rankin Scale. 
A

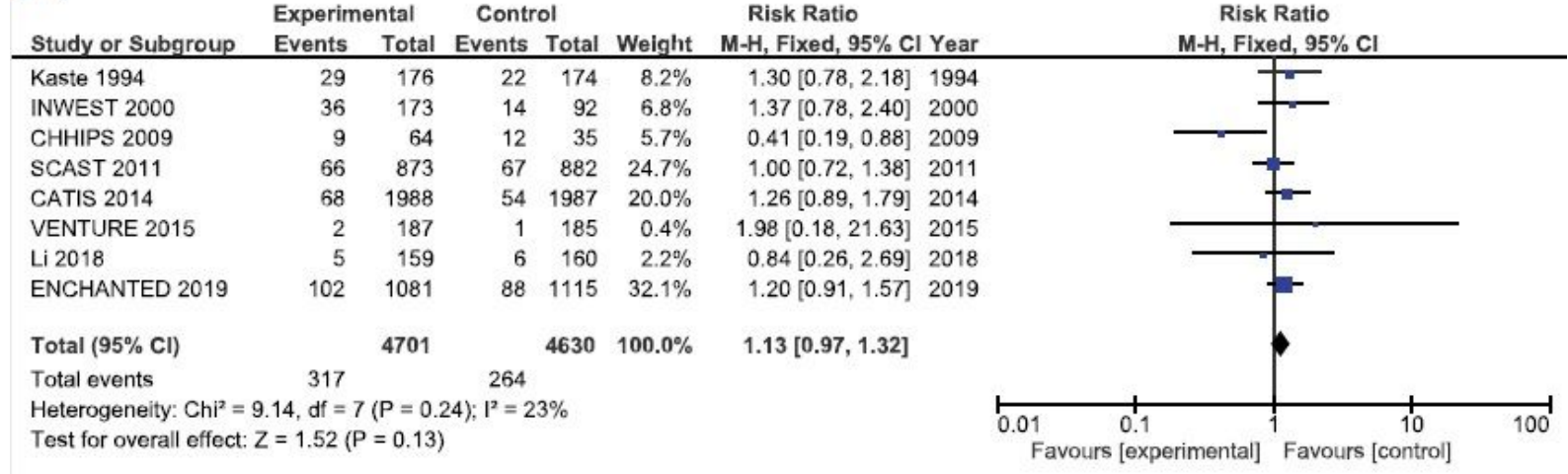

Experimental Control Risk Ratio

Risk Ratio

Study or Subgroup Events Total Events Total Weight M-H, Fixed, $95 \% \mathrm{Cl}$ Year

Kaste 1994

INWEST 2000

CHHIPS 2009

CATIS 2014

Li 2018

$\begin{array}{rr}20 & 176 \\ 36 & 173 \\ 5 & 64 \\ 25 & 2038 \\ 4 & 160\end{array}$

$2.82[1.23,6.51] 1994$

$\mathrm{M}-\mathrm{H}$, Fixed, $95 \% \mathrm{Cl}$

Total $(95 \% \mathrm{Cl})$

Total events

2611

90

$14 \quad 174 \quad 11.4 \%$

$1.37[0.78,240] 2000$

$0.55[0.17,1.76] 2009$

$1.00[0.57,1.73] 2014$

$252033 \quad 40.5 \%$

$0.80[0.22,2.92] 2018$

Heterogeneity: $\mathrm{Chi}^{2}=6.78, \mathrm{df}=4(\mathrm{P}=0.15) ;\left.\right|^{2}=41 \%$

Test for overall effect: $Z=1.37(P=0.17)$

$2494 \quad 100.0 \% \quad 1.25[0.91,1.73]$

C

\begin{tabular}{lrrrrrr} 
& \multicolumn{2}{c}{ Experimental } & \multicolumn{2}{c}{ Control } & \multicolumn{2}{c}{ Risk Ratio } \\
Study or Subgroup & Events & Total & Events & Total & Weight & M-H, Fixed, 95\% Cl Year \\
\hline Kaste 1994 & 29 & 176 & 22 & 174 & $8.8 \%$ & $1.30[0.78,2.18] 1994$
\end{tabular}

$1.30[0.78,2.18] 1994$

Kaste 1994

CHHIPS 2009

SCAST 2011

CATIS 2014

VENTURE 2015

Li 2018

$0.41[0.19,0.88] 2009$

$\begin{array}{rrrrr}67 & 882 & 26.5 \% & 1.00[0.72,1.38] & 2011 \\ 54 & 1987 & 21.4 \% & 1.26[0.89,1.79] & 2014\end{array}$

$\begin{array}{lrrr}873 & 67 & 882 & 26.5 \%\end{array}$

$\begin{array}{rrrr}1988 & 54 & 1987 & 21.4 \% \\ 187 & 1 & 185 & 0.4 \%\end{array}$

$1.98[0.18,21.63] 2015$

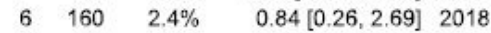

ENCHANTED 2019

5159

$88 \quad 1115 \quad 34.4 \%$

$1.20[0.91,1.57] 2019$

Total $(95 \% \mathrm{Cl})$

Total events

4528

$4538 \quad 100.0 \% \quad 1.11[0.94,1.31]$

Heterogeneity: $\mathrm{Chi}^{2}=8.63, \mathrm{df}=6(\mathrm{P}=0.20) ; \mathrm{I}^{2}=30 \%$

Test for overall effect: $Z=1.28(P=0.20)$

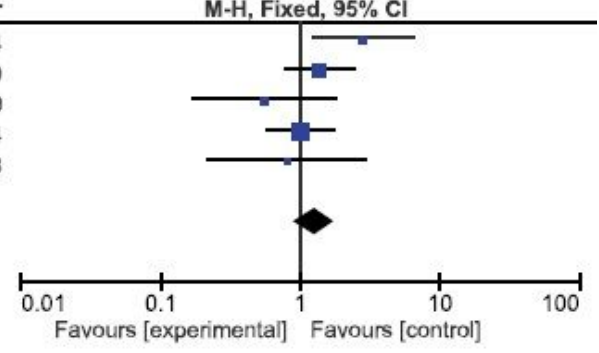

\section{Figure 5}

Comparison of mortality between the intervention and control groups. A. Mortality at the study follow-up endpoint. B. Short-term mortality. C. Long-term mortality. 


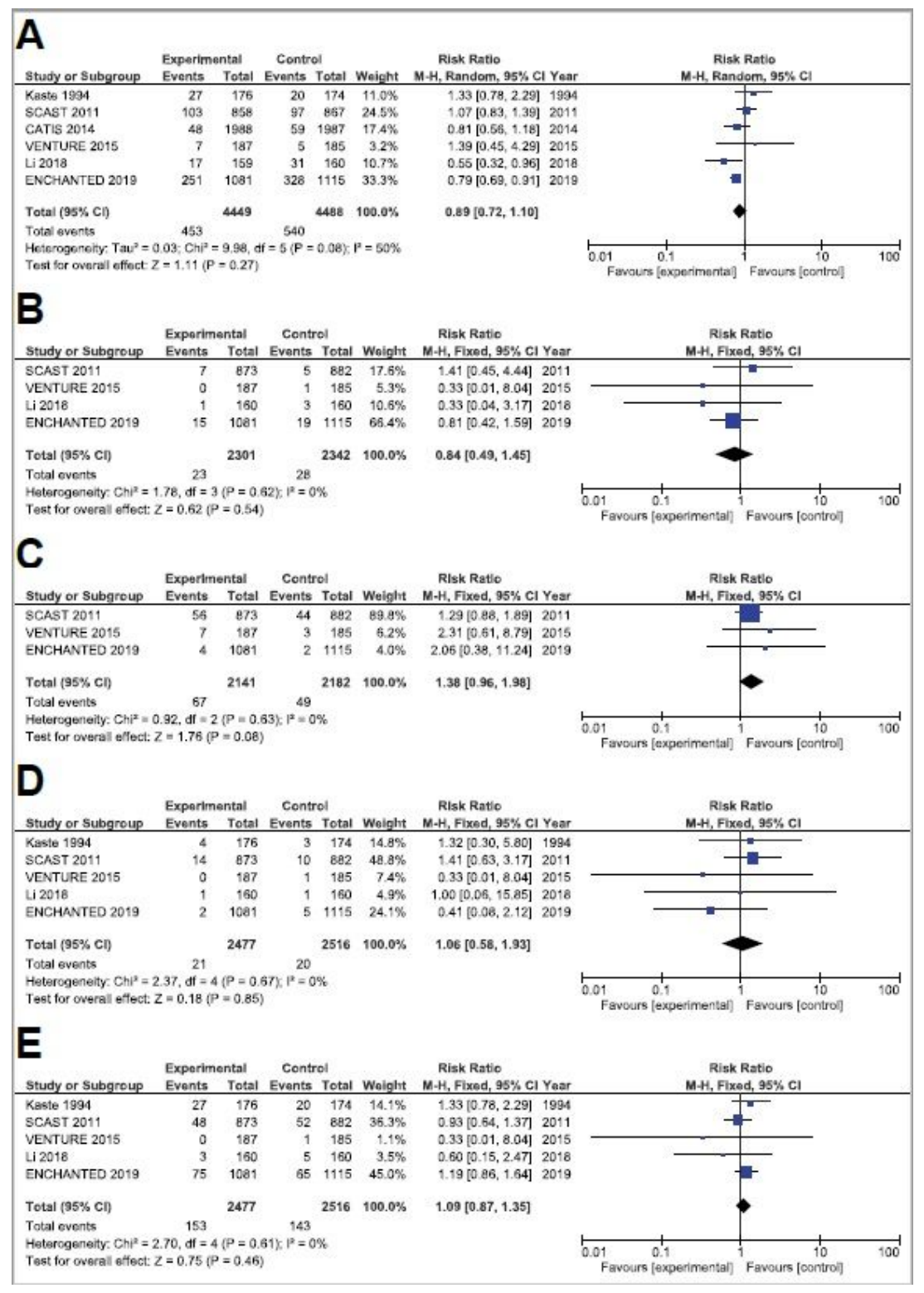

\section{Figure 6}

Comparison of safety outcomes between the intervention and control groups. A. Composite vascular endpoint: defined as the sum of vascular death, myocardial infarction or stroke events. B. Hemorrhagic stroke events. C. Ischemic stroke events. D. Myocardial infarction events. E. Vascular death.

\section{Supplementary Files}

This is a list of supplementary files associated with this preprint. Click to download.

- supplement10.doc

- supplement11.docx 